\title{
Um perfil de contadores de custos: estudo com profissionais de empresas do polo industrial de São Leopoldo, RS
}

\author{
Marcos Antonio de Souza \\ Doutorado em Controladoria e Contabilidade pela Universidade do Vale do Rio dos \\ Sinos - UNISINOS \\ Professor titular da Universidade do Vale do Rio dos Sinos - UNISINOS \\ Avenida Unisinos, 950. Bairro Cristo Rei. São Leopoldo/RS. CEP: 93.022-000 \\ E-mail:marcosas@unisinos.br \\ Tania Vanessa Sibirino Gomes \\ Calau Organizações Contábeis \\ Rua Pedro Peres, 45. Bairro Rio Branco. São Leopoldo/RS. CEP: 93.032-030 \\ E-mail: tabatavgomes@gmail.com
}

\section{RESUMO}

O objetivo do estudo é identificar o perfil pessoal e profissional dos contadores de custos atuantes em indústrias localizadas na cidade de São Leopoldo/RS. O desenvolvimento do estudo ampara-se no reconhecimento de que o contador de custos é altamente exigido na sua atuação como gerador de informação para a gestão organizacional. Trata-se de uma pesquisa de caráter exploratório, quantitativa e descritiva, desenvolvido no segundo semestre de 2011 e contou com a participação de uma amostra de 29 profissionais de custos, $83 \%$ deles atuando em empresas de médio e grande porte. A coleta de dados deu-se pela utilização de questionários construídos com perguntas abertas e fechadas e uso de escala do tipo Likert de cinco pontos. Os principais resultados evidenciam que $38 \%$ dos respondentes está há mais de 15 anos na atividade, sendo $97 \%$ deles já possuidores ou com formação acadêmica superior em curso. Os resultados também apontam que $72 \%$ dos respondentes são convidados a participar do processo decisório e estratégico da empresa, porém, nenhum deles ocupa cargo em nível de diretoria. Constata-se, também, a importância dada pelos profissionais pesquisados em desenvolver habilidades pessoais relativas à comunicação, relações humanas e de gestão. A iniciativa é reconhecida como um atributo de excelência profissional e habilidade chave requerida aos contadores de custos. Tópicos mais contemporâneos como a Gestão Estratégica de Custos são de conhecimento apenas mediano pelos respondentes.

Palavras-chave: Perfil Profissional. Habilidades. Contador de Custos.

A Profile of cost accountants: study with professionals of companies in industrial pole of São Leopoldo, RS 
Um perfil de contadores de custos: Estudo com profissionais de empresas do polo industrial de

São Leopoldo, RS

Marco Antonio Souza, Tania Vanessa Sibirino Gomes

\section{ABSTRACT}

This article aims to identify the personal and professional profile of cost accountants working for industries located in industrial pole of São Leopoldo City/RS. The study development support is the recognition that the cost accountant is under high demands on their performance in the generation of information to organization management. This is an exploratory study, quantitative and descriptive, developed in the second half of 2011 and with the participation of 29 professionals of costs, $83 \%$ of them working for medium and large companies. The data collection was constructed by using questionnaires with close and open questions and using the Likert scale of five points. The main finds show that $38 \%$ of respondents are over 15 years of activity, with $97 \%$ having or possessing higher academic course. The results also indicate that $72 \%$ of respondents are invited to participate in decision about strategic planning of the company, but none of them holds position level board. Respondents have given importance to developing professional skills for personal communication, human relation and management. There is recognition that the initiative is an attribute of professional excellence and a key skill required to cost accountant. Contemporary topics such as Strategic Management Cost are little known by respondents.

Keywords: Professional Profile. Skills. Cost Accountant.

\section{INTRODUÇÃO}

Tem sido abordado com frequência pela literatura relacionada à gestão empresarial, que no atual contexto de economia globalizada o desafio das organizações é manter-se competitiva diante das complexas transformações que o mundo dos negócios tem passado (PORTER, 1998).

Compreende-se que para uma empresa manter-se de forma sustentável no mercado ela tem que possuir alguns atributos que a tornem competitiva o suficiente em relação à concorrência. Em geral, essa habilidade da empresa tem sido configurada como a capacidade de suprir as necessidades dos seus clientes, incluindo-se ai os seus proprietários e outros agentes do mercado (BALLESTRO, 2001). Essa ênfase no foco das empresas, por vezes, pode não deixar transparente que as exigências de mercado também se aplicam a todas as entidades que nele atuam, sejam elas pessoas jurídicas ou físicas (COSENZA, 2001). Nessa realidade, o crescente nível de exigência impõe-se também a todos os tipos e áreas de atuação profissional. 
Um perfil de contadores de custos: Estudo com profissionais de empresas do polo industrial de

São Leopoldo, RS

Marco Antonio Souza, Tania Vanessa Sibirino Gomes

Essa realidade acaba por se constituir em um conjunto de habilidades que 0 profissional deve desenvolver, sejam elas de natureza profissional ou pessoal. Dado o foco deste estudo, um tipo específico de profissional chama atenção, ou seja, o profissional de custos. A maior exigência a esse profissional é uma decorrência natural, entre outros aspectos, do fato de que as empresas para alcançarem a continuidade sustentável antes tratada têm, na eficiência e eficácia do consumo de recursos, aqui tratados como custos, um pré-requisito. A literatura tem reconhecido que a informação contábil em geral, e a de custos em particular, têm desempenhado um papel relevante no suprimento das carências de informações que objetivam dar suporte ao processo decisório (SHANK; GOVINDARAJAN, 1997).

A esse respeito, conforme destacam ludícibus, Martins e Carvalho (2005), em função da evolução dos tempos e das organizações outros players interessados nas atividades das entidades foram surgindo, e suas demandas levaram a contabilidade a se transformar; passando de um engenhoso sistema de escrituração e elaboração de demonstrações contábeis simplificadas, para um complexo sistema de informação altamente estruturado, visando satisfazer a necessidade informacional dos usuários internos e externos das entidades.

Conforme acrescentam Cardoso, Souza e Almeida (2006), as exigências feitas pelo mercado de trabalho pertinente a mudança no perfil do contador de custos vêm ocorrendo ao longo dos anos, partindo da necessidade dos gestores das organizações que utilizam as informações contábeis para subsidiar a tomada de decisão.

Para que o profissional de custos se adapte às necessidades do mercado, ele deve acompanhar a evolução no cenário empresarial, desenvolvendo competências técnicas, pessoais e de entendimento de negócios, permitindo-Ihe aplicá-las em suas atividades profissionais, objetivando, dessa forma, atender as demandas informacionais, visando a excelência profissional (LOTHIAN, 1977; WILMSHURST; FROST, 2001). Observa-se, portanto, que esse profissional, a exemplo das empresas, também está presente em um mercado de elevada exigência e acirrada concorrência, 
Um perfil de contadores de custos: Estudo com profissionais de empresas do polo industrial de

São Leopoldo, RS

Marco Antonio Souza, Tania Vanessa Sibirino Gomes

para a qual ele deve estar preparado de forma a igualmente assegurar a sua continuidade sustentável.

Cardoso, Souza e Almeida (2006, p. 276) enfatizam que "no âmbito das transformações ambientais a que as empresas estão submetidas, entre elas o contínuo crescimento do nível de competição, novas exigências também se impõem a estes profissionais".

A complexidade de informações, e das operações mercantis tem exigido do contador de custos, não somente o aprimoramento de habilidades técnicas, mas também o desenvolvimento de suas habilidades pessoais e de padrões éticos. A esse respeito Raupp et al. (2009) salientam que os profissionais que se destacam no desafio da competição global são aqueles que estão mais preparados para enfrentá-la, ou seja, aqueles com melhor formação cultural e técnica.

Dessa forma, os contadores necessitam ampliar suas habilidades pessoais e habilidades técnicas na gestão de custos para atender de forma efetiva as organizações, para que de fato o profissional contábil cumpra sua missão e papel no âmbito dessas novas exigências que estão ocorrendo na contabilidade (CARDOSO; SOUZA; ALMEIDA, 2007).

Diante dessa breve contextualização do tema, emerge o problema de pesquisa: Qual o perfil do contador de custos atuante em empresas do pólo industrial de São Leopoldo/RS? Assim, diante do objetivo geral de identificar o perfil profissional do contador de custos, alguns objetivos específicos são colocados: (a) caracterizar as exigências de um mercado competitivo impostas às empresas quanto à gestão de custos de suas operações; (b) caracterizar as principais atividades da área de custos no contexto da disponibilização de informações para a eficiente e eficaz gestão de custos; (c) identificar a inserção do contador de custos no processo de gestão organizacional; (d) identificar, pela análise da literatura, quais as habilidades que delineiam o perfil do contador de custos da atualidade.

A relevância da pesquisa é dada à carência de estudos semelhantes aplicados para a região de pesquisa assim como para outras regiões do país. Alguns trabalhos 
Um perfil de contadores de custos: Estudo com profissionais de empresas do polo industrial de

São Leopoldo, RS

Marco Antonio Souza, Tania Vanessa Sibirino Gomes

foram localizados, mas, em sua maioria tratam do profissional contábil em geral, mas não no de custos em particular. O estudo também é uma resposta à citação de Cardoso (2006), o qual aponta que no Brasil há carência de pesquisas sobre competências do contador em comparação a estudos internacionais. Isso é mais acentuado quando se procura especificidades do contador de custos - algumas exceções são encontradas, como Silva e Miranda (2002); Callado, Miranda e Callado (2003).

O estudo contribui para que profissionais da área façam uma auto-avaliação a respeito do seu posicionamento e preparação nesse mercado de alta concorrência. Isso pode direcioná-los a ações que considerem necessárias para as respectivas atualizações. De outra parte, há também contribuição para as instituições de ensino superior no sentido delas examinarem e refletirem se o conteúdo do ensino que estão oferecendo está indo ao encontro das demandas de mercado.

Além disso, toda essa justificativa e relevância do estudo pode ser ratificada pelo entendimento dado por Franco (1999), o qual destaca que os contadores precisam ser treinados atualmente de forma diferente. Segundo Franco (1999, p. 83), além dos conhecimentos técnicos que são fundamentais, o contador de custos precisa desenvolver habilidades relativas à comunicação, relações humanas, administração, tendo um nivelamento ótimo entre a teoria e a prática. E conclui: "fundamental, o treinamento deve, doravante, ser baseado em dois pólos: educação inicial e educação continuada".

Além dessa introdução, o estudo contempla outras quatro seções. A primeira delas corresponde à contextualização teórica do tema; a segunda o destaque dos principais aspectos metodológicos da pesquisa; a terceira a apresentação, análise e discussão dos dados e resultados. Por fim, tem-se a conclusão do estudo, seguida da lista das referências utilizadas na sua construção. 
Um perfil de contadores de custos: Estudo com profissionais de empresas do polo industrial de

São Leopoldo, RS

Marco Antonio Souza, Tania Vanessa Sibirino Gomes

\section{FUNDAMENTAÇÃO TEÓRICA}

\subsection{O Perfil do Contador de Custos}

De acordo com Xavier (2006) há dois tipos de mudanças estruturais que impactam as carreiras profissionais: (a) mudanças conjunturais e (b) mudanças estruturais. As mudanças conjunturais decorrem de modificações imediatas que ocorrem entre os agentes econômicos (empresas, clientes, funcionários, governo, concorrentes), são mudanças de curto prazo e em geral passageiras. Por exemplo: variações do dólar, inflação, vendas de empresas. No entanto, as mudanças estruturais, mais profundas, decorrem de impactos maiores como a tecnologia, valores sociais, política e grandes movimentos econômicos, como por exemplo, a globalização.

Xavier (2006) acrescenta que as principais mudanças que estão afetando o mercado de trabalho e o desenvolvimento das carreiras, são:

a) Globalização: o maior trânsito de produtos, serviços e recursos cria novas oportunidades e ameaças. Os níveis de preços e produtividade são fixados em padrão internacional e as empresas que estão fora desse padrão devem se adaptar para se manterem no mercado;

b) Trade-off: diz respeito ao deslocamento da força de trabalho. Com o aumento da automatização em grandes indústrias, o número de demissões é considerável e, como consequência, os profissionais tendem a migrar para o setor de serviços, ou para empresas industriais de menor porte;

c) Concentração de negócios: com o aumento da competitividade as empresas têm feito fusões - as com maior poder econômico comprando concorrentes. Esse movimento dos negócios traz oportunidades profissionais para ocupar cargos de maiores responsabilidades;

d) Níveis de exigências crescentes: o elevado nível de exigência dos clientes tem refletido em profissionais de qualquer área, dado que a busca pela qualidade e excelência empresarial, levam os profissionais a se qualificarem cada vez mais. 
Um perfil de contadores de custos: Estudo com profissionais de empresas do polo industrial de

São Leopoldo, RS

Marco Antonio Souza, Tania Vanessa Sibirino Gomes

Dado que essas mudanças tratadas pelo autor têm repercussão indiscriminada em todas as áreas de atuação, entende-se que elas têm afetado também os profissionais da contabilidade (KAVCIC; MIHELCIC, 2006). De fato, são mudanças estruturais dentro das organizações, consequência da globalização e do aumento da competitividade, que trazem maiores exigências quanto aos atributos do fluxo de informações. Considerando serem elas (as informações) o principal produto da área contábil, a consequência é esses profissionais serem mais exigidos quanto às capacitações exigidas para atender as novas demandas, quer no âmbito profissional ou pessoal. Esse entendimento é corroborado por Cardoso, Souza e Almeida (2006).

Pires (2008) destaca que as exigências feitas pelo mercado de trabalho, pertinente a mudança no perfil do profissional contábil parte principalmente das exigências dos gestores organizacionais que utilizam informações contábeis para tomada de decisão. A autora acrescenta que a automatização contábil dos registros das transações também colaborou para liberar o profissional contábil dessas atividades mecânicas. De fato, na atualidade, os sistemas contábeis se encarregam de processar os dados, integrá-los e transformá-los em informações, cabendo ao contador analisálos, para subsidiar a tomada de decisão dos gestores.

No entendimento de Mohamed e Lashine (2003) alterações têm ocorrido na forma de atuação dos contadores. Tanto a globalização de mercados como as inovações em $\mathrm{TI}$ são fatores frequentemente citados. Os autores acrescentam que o desenvolvimento contínuo de competências, habilidades e conhecimentos passaram a ser entendidos como pré-requisitos a profissionais interessados em permanecer no mercado de forma sustentável. Isso conduz ao entendimento de que o contador necessita ser criativo e inovador

Neste novo ambiente, a participação mais ativa no processo de gestão passou a integrar o perfil do profissional contábil, implicando que na atualidade é insuficiente deter somente conhecimento técnico em contabilidade. Cosenza (2001) alerta que aqueles profissionais que hoje ainda ficam presos ao passado e só conhecem, 
Um perfil de contadores de custos: Estudo com profissionais de empresas do polo industrial de

São Leopoldo, RS

Marco Antonio Souza, Tania Vanessa Sibirino Gomes

exclusivamente, a contabilidade em termos de partidas dobradas, debitando e creditando sem agregar nenhum valor à empresa, estão com seus dias contados.

Apesar de toda a ênfase à contabilidade, manifestações específicas sobre a relevância da contabilidade de custos na gestão empresarial também são encontradas. Isso pode ser constatado na obra de Martins (2003, p.2), para o qual a "a Contabilidade de Custos passou a ser encarada como eficiente instrumento de suporte no desempenho da missão gerencial das empresas, em especial nas funções de controle e tomada de decisões". Assim, a partir do momento que o contador de custos estiver apto a fazer parte da gestão da entidade ele estará consolidando sua competência profissional.

O objetivo de caracterizar o perfil do contador de custos também está presente em outros estudos. É o caso de Silva e Miranda (2002), que abordaram o contador de custos nas indústrias de transformação do estado de Pernambuco. No estudo é ratificada a preparação do contador de custos para participar da gestão organizacional. Os autores enfatizam que este profissional, mesmo que de forma indireta, participa dos atos decisórios da organização, via fornecimento de informações para as deliberações. Assim, compreender essas necessidades e formatar sistemas e técnicas de informações que tornam possível esse fornecimento é uma habilidade profissional que carece de desenvolvimento constante.

A necessidade de um perfil do gestor de custos mais adequado à realidade das organizações também foi discutido por Callado, Miranda e Callado (2003). Os autores exploraram a descrição das habilidades tecnológicas de TI, formação acadêmica e pessoal, todas elas como requisitos para o avanço do contador na posição hierárquica organizacional.

Kavcic e Mihelcic (2006) concentraram-se em analisar especificamente as seguintes características do campo de atuação do profissional de custos: (a) a contabilização das operações representa uma pequena parte das tarefas dos contadores das grandes empresas; (b) os contadores devem conhecer a natureza dos negócios da empresa e estabelecer os recursos informacionais, em diferentes níveis, 
Um perfil de contadores de custos: Estudo com profissionais de empresas do polo industrial de

São Leopoldo, RS

Marco Antonio Souza, Tania Vanessa Sibirino Gomes

internos e externos à empresa; (c) eles podem utilizar suas habilidades de relações interpessoais em seu benefício, tanto ao estabelecer canais informais de informação, como também quando conduz e orienta seus subordinados, ajudando a desenvolver a sua vantagem competitiva; (d) no campo contábil, tecnologia e inovação intelectual são práticas comuns; o novo sistema de gestão tem utilização intensa de novas tecnologias de informação, às quais os contadores precisam desenvolver habilidade de uso.

Outro foco que tem se destacado como exigência aos profissionais de custos refere-se à gestão estratégica de custos (GEC). Os trabalhos de Simmonds (1981) e Shank e Govindarajan (1997) destacam a necessidade dos profissionais de custos desenvolverem habilidades necessárias ao desenvolvimento e uso da informação de custos em face às demandas da gestão estratégica de custos. Porter (1998) trata da informação de custos na obtenção de vantagem competitiva em relação à concorrência e destaca o papel dos contadores de custos nesse novo foco. Tem-se assim a arquitetura de um perfil do contador de custos formatado com base em novas habilidades pessoais e profissionais.

\subsection{Competência Profissional}

Para o contador de custos integrar a gestão empresarial, deve acompanhar as alterações no cenário empresarial e desenvolver competências para evoluir em suas atividades. Para Vergara (2000, p. 38), competência é "uma capacidade especifica de executar a ação em um nível de habilidade suficiente para alcançar o efeito desejado".

Fleury e Fleury (2001) destacam que competência é a palavra utilizada para designar uma pessoa qualificada para realizar algo. Mencionam que não se pode confundir qualificação com competência. Enquanto a qualificação está associada à posição ou cargo, ou ao estoque de conhecimento que pode ser obtido pelo indivíduo, classificado e certificado pelo sistema educacional, a competência vai além e se refere à capacidade do indivíduo em ter iniciativa, ser capaz de compreender e dominar novas situações de trabalho. 
Um perfil de contadores de custos: Estudo com profissionais de empresas do polo industrial de

São Leopoldo, RS

Marco Antonio Souza, Tania Vanessa Sibirino Gomes

Observa-se, portanto, que a competência profissional não está somente ligada à teoria, necessitando ser completada pelas experiências práticas, principalmente no desenvolvimento das habilidades pessoais. Isso está contemplado na afirmativa de Le Boterf (2003), o qual conceitua a competência como uma ligação de três eixos formados pelo indivíduo (sua biografia, socialização; por sua formação educacional e por sua experiência profissional).

Durand (1998) tratou dessas questões e idealizou o conceito de competência baseado em três dimensões: conhecimentos, habilidades e atitudes. Na visão do autor, essas dimensões são interdependentes uma vez que para expor uma habilidade se presume que o indivíduo conheça princípios e técnicas para tal, conceituando-as da seguinte forma: (a) conhecimento - capacidade de assimilar a informação de forma estruturada, permitindo que o indivíduo a compreenda; (b) capacidade - aptidão de receber a informação e integrá-la dentro de um pensamento pré-existente, saber o que fazer com ela, aplicando as técnicas vivenciadas e suas aptidões, o que corre pelo treinamento e experiência prática; (c) atitude - aspectos afetivos e sociais no ambiente de trabalho, se comprometendo com os valores da organização para atender aos padrões de comportamento esperados e atingir os resultados esperados. Para o autor, da junção dessas três dimensões surge a competência. Zarifian (2001, p. 67) corrobora com o pensamento de Durand, ao entender essas três dimensões como "uma combinação de conhecimentos, de saber fazer, de experiências e comportamentos que se exerce em um contexto preciso. Ela é constatada quando de sua utilização em situação profissional, a partir da qual é passível de validação".

O American Institute of Certified Public Accountants - AICPA, apresentou por meio de seu relatório final o projeto CPA Horizonts 2025, uma visão de cinco competências essências ao contador certificado (CPA). As competências essências requerem uma combinação ótima de conhecimento, habilidades humanas e tecnologia, fornecendo valor e resultados para os usuários internos e externos. Os autores reiteram que reforçar as nossas competências é fundamental para sustentar uma vantagem 
Um perfil de contadores de custos: Estudo com profissionais de empresas do polo industrial de São Leopoldo, RS Marco Antonio Souza, Tania Vanessa Sibirino Gomes

competitiva e diferencial no mercado (AICPA, 2011). Essas habilidades consideradas CPA estão resumidas no Quadro 1.

\begin{tabular}{|c|l|}
\hline Comunicação e Habilidades de Liderança & $\begin{array}{l}\text { Ser capaz de dar e trocar informações em um } \\
\text { contexto significativo; ser capaz de influenciar, } \\
\text { inspirar e motivar sua equipe a alcançar resultados. }\end{array}$ \\
\hline Pensamento Estratégico e Crítico & $\begin{array}{l}\text { Vincular dados, conhecimentos e novas idéias para } \\
\text { aconselhar com qualidade a tomada de decisão } \\
\text { estratégica. }\end{array}$ \\
\hline Foco no Cliente e no Mercado & $\begin{array}{l}\text { Antecipar e satisfazer as necessidades dos } \\
\text { usuários melhor que os concorrentes. Conhecer as } \\
\text { tendências de mercado atuais e emergentes de } \\
\text { forma ativa e continuada. }\end{array}$ \\
\hline Interpretação da Informação Convergente \\
\hline Tecnologicamente Apto & $\begin{array}{l}\text { Ser capaz de interpretar e fornecer um contexto } \\
\text { mais amplo, usando informações financeiras e não } \\
\text { financeiras. Fazer uso de informações tangíveis e } \\
\text { intangíveis para fornecer interpretações que são } \\
\text { oportunas e de valor. }\end{array}$ \\
\hline $\begin{array}{l}\text { Empregar a tecnologia de forma a agregar valor aos } \\
\text { clientes e aos empregadores. }\end{array}$ \\
\hline
\end{tabular}

Quadro 1 - Cinco Competências Essenciais para o AICPA Fonte: AICPA (2011).

Nota-se que há um movimento contínuo em agregar habilidades que reflitam na gestão da organização como um todo. No estudo desenvolvido pelo Sindicato dos Contabilistas de São Paulo - SINDCONTSP (2005) há reconhecimento de que o conhecimento científico da contabilidade, tão necessário nos dias atuais, quando visto isoladamente é insuficiente para a eficaz atuação do contabilista. Nesse estudo foi apontado que o contador deve manter atitude ética, ser flexível a mudanças, ser estudioso e ter postura de líder.

\subsection{Habilidades Pessoais}

Le Boterf (2003, p. 125) enfatiza que as "competências comportamentais assumem cada vez mais importância no exercício de uma profissão". O autor conclui que as seguintes características são fundamentais: "capacidade de escuta, atitudes de acolhida, capacidade de iniciativa, tenacidade e a autoconfiança [...]". 
Um perfil de contadores de custos: Estudo com profissionais de empresas do polo industrial de São Leopoldo, RS Marco Antonio Souza, Tania Vanessa Sibirino Gomes

Rhinesmith (1993 apud VERGARA, 2000) consolida como habilidades pessoais necessárias as seguintes: (a) flexibilidade: adaptação para lidar com as mudanças do ambiente, permitindo ações rápidas frente a mudanças nos processos; (b) sensibilidade: necessária para lidar com diferenças individuais, não apenas ter integração emocional com a equipe, mas estar aberto para outros pontos de vista e predisposto a questionar suposições, valores e convicções.

Conforme Cardoso, Souza e Almeida (2006) e Carvalho (2009), as exigências ao contador de custos, entre outros profissionais, envolvem as seguintes habilidades pessoais:

a) Comunicação interpessoal - boa articulação ao comunicar suas idéias e apresentações (escritas ou verbais); saber entender e dialogar demonstrando corretamente os conceitos e critérios utilizados no sistema de informação de custos; bom relacionamento interpessoal com membros da equipe;

b) Liderança - ressalta a importância de uma relação clara e bem definida para obter a cooperação dos colaboradores e gestores das outras áreas da organização visando um sistema ótimo de informação contábil. O relacionamento entre o contador de custos e os demais gestores deve se basear na oferta de apoio na solução dos problemas que os gestores defrontam nas suas atividades cotidianas;

c) Postura ética - O profissional contábil deve desempenhar suas atividades com honestidade, independência e lisura, com base nos princípios fundamentais de contabilidade, nas normas brasileiras de contabilidade e no código de ética;

d) Responsabilidade ambiental e social - O contador de custos deve ver o desempenho ambiental e econômico como complementares; o ambiental não pode ser visto como um assunto de caridade, mas como fator competitivo a ser explorado. Reduzir custos ambientais pode criar vantagem competitiva (FRIEDRICH; ALMEIDA, 2003). 
Um perfil de contadores de custos: Estudo com profissionais de empresas do polo industrial de

São Leopoldo, RS

Marco Antonio Souza, Tania Vanessa Sibirino Gomes

\subsection{Habilidades Técnicas}

De acordo com Le Boterf (2003), conhecer técnicas ou regras de gestão de custos não assegura excelência profissional. Sabe-se que na prática muitas pessoas possuem conhecimento técnico, mas não sabem mobilizá-los de modo pertinente e no momento oportuno da situação profissional. O autor completa que "um bom profissional sabe não somente dominar uma técnica, mas também executá-la em um contexto de competitividade e de estresse" (LE BOTERF, 2003, p. 49).

Zarifian (2001) observa que deve haver, simultaneamente, o desenvolvimento de métodos e ferramentas específicos de mensuração e técnicas de desempenho com o modo de executar os atos técnicos. Para que o contador de custos cumpra adequadamente o seu papel dentro da organização, habilidades técnicas são requeridas a respeito da gestão de custos e da gestão estratégica de custos. Dentre as principais, destacam-se as seguintes:

a) Gestor da informação - A informação como produto final de um sistema de informação deve ser disseminada para auxiliar no processo decisório. Perez Júnior, Oliveira e Costa (2010) destacam que pelos sistemas de informação o contador de custos pode elaborar relatórios com informações relevantes;

b) Domínio de métodos quantitativos - Alguns problemas encontrados pelo contador de custos só podem ser resolvidos com aplicação de instrumentos matemáticos e estatísticos (LEONE; LEONE 2010). Essas habilidades são necessárias para que o contador de custos exerça com excelência, a resolução de questões complexas;

c) Capacidade de alavancar e usar a tecnologia - No final do século $X X$ intensificaram-se os investimentos em sistemas integrados de gestão Enterprise Resourcing Planning (ERP) e Business Intelligence (BI) cujo objetivo é automatizar todo o fluxo de informação operacional. Para Carvalho (2009), o contador de custos deve estar familiarizado com esses sistemas, pois com eles a informação a respeitos dos custos pode se explorada em diferentes perspectivas. 
Um perfil de contadores de custos: Estudo com profissionais de empresas do polo industrial de

São Leopoldo, RS

Marco Antonio Souza, Tania Vanessa Sibirino Gomes

\subsection{Entendimento de Negócios}

Ao contador de custos é importante deter entendimento amplo dos negócios da organização. A esse respeito, Fleury e Fleury (2001, p. 24) conceituam competência para negócios como "competências relacionadas à compreensão do negócio, seus objetivos em relação aos mercados, clientes e competidores, assim como com ambiente político e social. "

Observa-se, que conhecer os segmentos da indústria, ter perspectiva do cenário competitivo global, e estar ciente das implicações legais e fiscais do negócio, viabilizam que o contador de custos possa contribuir de forma adequada com a gestão focando no ambiente externo (clientes, concorrentes, governo e acionistas) e interno (gestores).

Para Xavier (2006), no âmbito de atuação da organização, no que diz respeito ao local, região ou escala global, é importante o profissional ter entendimento de qual cenário a organização está submetida. Isso é necessário para que ele possa focar seus conhecimentos específicos na sua área de atuação, no caso a contabilidade de custos, ou mesmo em outro estágio como na gestão estratégica de custos.

Fleury e Fleury (2001) abordam que no passado a visão estratégica era essencial aos gestores de alta administração. $\mathrm{Na}$ atualidade essa visão tem que estar presente em todos os níveis profissionais, integrando as competências do indivíduo.

Carvalho (2009) também reconhece que a visão do contador de custos deve ser interdisciplinar criando conexões entre as áreas (comerciais, vendas, marketing, administrativas, humanas e técnicas) em um contexto do mercado onde a organização está inserida. Carvalho (2009) complementa que é importante que o profissional compreenda o que está acontecendo no ambiente externo e na sua empresa. Isso é necessário para que se possa entender e antecipar problemas sem impulsividade, procurando responder positivamente às necessidades da organização.

Para Hansen e Mowen (2001) é importante que o contador de custos compreenda os vários processos do produto dentro da organização, de manufatura a marketing, distribuição e serviços ao cliente. Para os autores, esta posição mais inclusiva do contador de custos traz a ele uma visão mais completa do custo desde o 
Um perfil de contadores de custos: Estudo com profissionais de empresas do polo industrial de

São Leopoldo, RS

Marco Antonio Souza, Tania Vanessa Sibirino Gomes

projeto inicial do produto, bem como no processo de produção, distribuição, vendas e atendimento ao cliente.

No entendimento de Dutra (2007), as habilidades técnicas e pessoais que os profissionais precisam adquirir, devem ter relação direta com as estratégias da organização. Além disso, a preocupação com o aprendizado contínuo dentro da organização é um aspecto a ser considerado. Sobre isso Mcgee e Prusak (1994, p. 206) destacam que

[...] Como impulso para mudança, aprendizado significa observar o ambiente para detectar sinais fortes ou fracos, sintomas precoces de ameaças ou oportunidades. É detectar mudanças que ameaçam ampliar o distanciamento entre as exigências ambientais e o fundamento atual de uma organização.

Para Fleury e Fleury (2001) o processo de aprendizado e criação de novas competências é um círculo virtuoso nas empresas, além de ser útil dada a necessidade de implantar estratégia competitiva com sucesso. Pode-se concluir que a capacidade de se adaptar em ambientes de constantes mudanças é um diferencial do profissional de custos.

\section{ASPECTOS METODOLÓGICOS}

\subsection{Classificação da Pesquisa}

Conforme Vergara (2000), para classificação da pesquisa toma-se como base dois critérios: (a) pesquisa quanto aos fins; (b) pesquisa quanto aos meios. Para atingir os objetivos deste estudo, o tipo de pesquisa utilizado, quanto aos fins, é o descritivo, pois o objetivo do estudo é descrever as características de determinada população, no caso os contadores de custos quanto ao seu perfil.

A respeito das características básicas da pesquisa descritiva, Gil (2010, p. 27-28) salienta que elas "têm por objetivo estudar as características de um grupo: sua 
Um perfil de contadores de custos: Estudo com profissionais de empresas do polo industrial de

São Leopoldo, RS

Marco Antonio Souza, Tania Vanessa Sibirino Gomes

distribuição por idade, sexo, procedência, nível de escolaridade [...]”. Roesch (2010) corrobora o entendimento de Gil (2010) ao recomendar que ela seja apropriada para obter informação sobre determinada população a respeito de suas características. $O$ estudo também é classificado como exploratório visto que, conforme Vergara (2000) é realizado em uma área onde há pouco conhecimento acumulado e sistematizado.

Quantos aos meios, a investigação foi feita por meio de pesquisa de campo, a qual, de acordo com Vergara (2000) pode incluir entrevistas, questionários, testes e observação participante ou não.

\subsection{População Amostral}

Conforme Vergara (2000, p. 50), "população amostral ou amostra é uma parte do universo (população) escolhida segundo algum critério de representatividade". O tipo de amostra é não probabilístico. Vergara (2000) destaca dois critérios de seleção: (a) por acessibilidade; (b) por tipicidade.

Para fins deste estudo foi usado o critério por tipicidade, constituída pela seleção de elementos que são considerados representativos para atingir a população-alvo. Dados os objetivos do estudo, a população amostral examinada foi a dos contadores de custos de empresas do pólo industrial de São Leopoldo/RS.

\subsection{Coleta de Dados}

O processo de coleta de dados desenvolveu-se por meio de algumas atividades especificas. Primeiramente foi obtido junto à Prefeitura Municipal de São Leopoldo um cadastro das indústrias estabelecidas na cidade, posição no ano base 2009 (último disponível), totalizando 402 indústrias. Em seguida, as indústrias foram classificadas pelo seu porte, adotando-se para tal os critérios estabelecidos pelo BNDES (2011).

Segundo o BNDES (2011), o porte das empresas é determinado pela receita operacional bruta anual ou anualizada, em milhões de reais, a saber: (a) Microempresas - até $R \$ 2,4$; (b) Pequenas Empresas - entre $R \$ 2,4$ e $R \$ 16,0$; (c) Médias Empresas - entre $R \$ 16,0$ e $R \$ 90,0$; (d) Médias-Grandes Empresas - entre $R \$$ 
Um perfil de contadores de custos: Estudo com profissionais de empresas do polo industrial de

São Leopoldo, RS

Marco Antonio Souza, Tania Vanessa Sibirino Gomes

90,0 e $\mathrm{R} \$ 300,0$; (e) Grandes Empresas - acima de $\mathrm{R} \$ 300,0$. Adotando-se esses critérios do BNDES, e excluindo-se as Micro e as Pequenas Empresas, chegou-se à população alvo de 40 empresas.

Foi feito contato telefônico com os contadores dessas 40 empresas, esclarecendo os aspectos gerais das pesquisas e solicitando participação. A todos foi enviado o instrumento de pesquisa, por email, obtendo-se 29 retornos, equivalente a $72,5 \%$ da população-alvo.

O instrumento foi elaborado com o uso, em sua maioria, de assertivas, com a utilização de escala do tipo Likert de cinco pontos. Tem-se, assim, caracterizada uma survey.

\subsection{Análises dos Dados}

Os dados foram tratados de forma quantitativa, utilizando-se a análise percentual e a participação relativa na mensuração da sua representatividade.

Conforme Roesch (2010, p. 150), em uma análise quantitativa "pode-se calcular médias, computar percentagens, examinar os dados para verificar se possuem significância estatística [...] estas análises permitam extrair o sentido dos dados, comparando resultados".

Foi utilizada a escala tipo Likert com vistas a medir a intensidade das respostas. Conforme mencionado por Roesch (2010), o valores das escalas permitem calcular o Ranking Médio (RM), possibilitando, assim, a estatística descritiva global do conjunto analisado.

A lógica utilizada na pontuação das escalas significa que quanto mais próxima for da escala cinco, maior é concordância do respondente quanto à afirmativa apresentada. De outra parte, quanto mais próxima da escala 1, maior é a discordância.

Por fim, os resultados obtidos são examinados em relação ao exposto no referencial teórico pertinente à temática considerada no estudo. 
Um perfil de contadores de custos: Estudo com profissionais de empresas do polo industrial de

São Leopoldo, RS

Marco Antonio Souza, Tania Vanessa Sibirino Gomes

\section{RESULTADOS E ANÁLISE}

\subsection{Perfil das Empresas}

Do total de 29 contadores respondentes que participaram da pesquisa, 52\% atuam em médias-empresas, $21 \%$ em médias-grandes empresas, $10 \%$ em grande empresa e os demais $17 \%$ em pequenas empresas, assim classificadas por grandeza de faturamento bruto conforme critério adotado pelo BNDES (2010). Observa-se que em sua maioria são empresas de expressiva representatividade econômica.

Quanto ao tipo jurídico de constituição das empresas, $62,1 \%$ são de responsabilidade limitada e $27,6 \%$ sociedades anônimas de capital fechado. Apenas $20,7 \%$ dos profissionais atuam em empresas estrangeiras. Considerando a sede empresarial, $72,4 \%$ dos respondentes atuam na empresa matriz e $27,6 \%$ em filiais.

Após essa breve descrição do perfil das empresas empregadoras, apresentamse nas seções seguintes os principais aspectos do perfil dos profissionais participantes.

\subsection{Características Gerais}

Dentre os diversos critérios de caracterização dos respondentes observa-se que o gênero feminino, apesar de em menor quantidade, é representativo em $41 \%$, equivalente a 12 participantes. Quanto à expressiva participação feminina, o estudo de Rosa (2008) também evidenciou que a mulher está se destacando neste campo de trabalho.

Outro elemento do perfil dos respondentes, a faixa etária, mostra que mais da metade deles (52\%) encontra-se na faixa de 41 a 55 anos, representando idade de maturidade pessoal. Essa maturidade também está expressa no tempo de atuação na área (48\% acima de 10 anos; $21 \%$ de 6 a 10 anos). No estudo desenvolvido por Callado Miranda e Callado (2003), $77 \%$ dos entrevistados se encontravam na faixa etária entre 31 a 50 anos, bastante próxima deste estudo.

O estudo desses autores evidenciou também que $40 \%$ dos gestores de custos possuem entre 11 e 20 anos de experiência no cargo. Esses dados corroboram a conclusão 
Um perfil de contadores de custos: Estudo com profissionais de empresas do polo industrial de

São Leopoldo, RS

Marco Antonio Souza, Tania Vanessa Sibirino Gomes

de Cardoso, Souza e Almeida (2006), que profissionais da área contábil costumam apresentar alta estabilidade ocupacional. Ainda nesse contexto, identificou-se que $75 \%$ dos componentes da amostra iniciou suas atividades na área antes ou durante o estudo da graduação. Assim, observa-se que para maioria dos respondentes a formação profissional inicial deu-se de forma simultânea à formação acadêmica.

\subsection{Formação Acadêmica e Ações de Atualização Profissional}

Quanto à formação acadêmica, $51 \%$ da amostra têm curso superior completo, 34\% em Ciências Contábeis. Outros 14\% estão com curso superior em andamento. Portanto, $75 \%$ da amostra é formada ou está em formação superior. $31 \%$ dos respondentes informam já ter concluído uma pós-graduação (14\% especialista, 14\% MBA e $3 \%$ mestrado). Portanto, em sua maioria a amostra revela atenção a uma formação acadêmica superior.

Apesar da forte presença de livros (61\%), revistas e artigos científicos (34\%) e revistas e jornais (59\%), a internet, com $93 \%$ é a fonte mais utilizada para atualização nos requisitos profissionais. Chama atenção a baixa presença em congressos (21\%) e comunicados do Conselho Regional e Conselho Federal de Contabilidade (28\%), principais entidades representativas dos profissionais da contabilidade.

Dentre as fontes de conhecimento contínuo utilizadas pelos respondentes, a maioria (93\%) declarou fazer uso da própria experiência prática, seguida de leitura especializada (59\%). Cursos na empresa (28\%) e cursos extracurriculares (45\%) são as demais fontes de maior uso. Observa-se que, no geral, há preocupação com o acompanhamento e atualização dos desenvolvimentos da área. Talvez se tenha aqui a necessidade de estudos de maior detalhamento para identificações mais precisas sobre os cursos frequentados.

Os resultados quanto a fontes de atualização são superiores aos do estudo de Silva e Miranda (2002), no qual a maior parte dos entrevistados declarou participar apenas uma vez ao ano em eventos como cursos, palestras e seminários. De qualquer forma, há consistência com os resultados do estudo de Silva e Miranda (2002), dada 
Um perfil de contadores de custos: Estudo com profissionais de empresas do polo industrial de

São Leopoldo, RS

Marco Antonio Souza, Tania Vanessa Sibirino Gomes

a predominância da experiência prática (100\%), literatura especializada (81\%) e cursos específicos (75\%).

\subsection{Posição Organizacional}

Sabe-se que é variada a terminologia aplicada aos cargos da área contábil. Os dados da pesquisa indicam que a maioria dos participantes (34\%) encontra-se enquadrado na nomenclatura clássica de contador geral. Com cargos mais específicos tem-se analista de custos (10\%), analista de custos sênior (7\%), controller (14\%), (10\%) supervisor de custos e chefe de custos (3\%). Assim, o perfil dos respondentes tem majoritária participação (47\%) de profissionais com atuação específica em custos. Acrescente-se que $21 \%$ declararam diversas nomenclaturas de cargos (outras). Também chama atenção a ausência de profissionais em cargos de diretoria: $41 \% \mathrm{em}$ cargos de gerência, 34\% supervisão/coordenação e $24 \%$ em cargos de assessoria.

O resultado desta pesquisa corrobora aquele encontrado no estudo de Cardoso, Souza e Almeida (2006), o qual apontou que somente um contador está em posição de diretoria, também prevalecendo nos demais os gerentes e supervisores.

Apesar da posição organizacional intermediária dos respondentes, dados específicos da pesquisa indicam que a participação deles no processo decisório e na formação da estratégia organizacional é destacada, correspondendo a $72 \%$ entre convidado e geralmente ouvido pela direção. No estudo de Silva e Miranda (2002), os autores constataram que apenas $31 \%$ dos profissionais são sempre convidados a opinar e 50\% poucas vezes são convidados a opinar. Os resultados obtidos revelam, portanto, um avanço na participação dos contadores de custos no processo decisório, em relação ao estudo de Silva e Miranda (2002).

\subsection{Principais Atribuições}

Dentre as atribuições mais indicadas, $69 \%$ dos respondentes destacaram a elaboração de relatórios gerenciais, a segunda maior indicação individual (66\%) marca os trabalhos de análise de custos e $59 \%$ referiram as atribuições tributárias e gerenciais 
Um perfil de contadores de custos: Estudo com profissionais de empresas do polo industrial de

São Leopoldo, RS

Marco Antonio Souza, Tania Vanessa Sibirino Gomes

da contabilidade geral. Também se encontram acima de $50 \%$ as atividades da contabilidade de custos.

Apesar de toda ênfase dada pela literatura relacionada a custos, a indicação de atividades relacionadas à gestão estratégica de custos recebeu indicação mais reduzida, situada em 38\%. Quanto às principais práticas de gestão de custos adotadas, observa-se a predominância de uma contabilidade de custos ainda tradicional, predominando a margem de contribuição $(76 \%)$, custeio por absorção $(38 \%)$ e custopadrão (28\%).

Conforme destacado no relatório do projeto CPA Horizonts 2025 (AICPA, 2011), o uso da tecnologia integra as cinco competências essenciais requeridas ao contador. Quanto ao nível de conhecimento em sistemas integrados, 45\% dos respondentes afirmaram possuir nível apenas intermediário; 38\% mostram maior domínio, classificado como avançado. Há também o extremo de conhecimento básico e nenhum conhecimento, declarado por $17 \%$ da amostra. Esse resultado é menos favorável do que o do estudo de Cardoso, Souza e Almeida (2006), o qual evidenciou que $70 \%$ dos profissionais possuíam conhecimento entre básico e intermediário.

\subsection{Práticas de Gestão Estratégica de Custos Conhecidas}

A gestão estratégica de custos - GEC tem estado presente no âmbito da literatura que trata da gestão organizacional. Dada essa realidade, indagou-se aos respondentes acerca do seu conhecimento quanto a tais práticas (Tabela 1). 
Um perfil de contadores de custos: Estudo com profissionais de empresas do polo industrial de

Tabela 1 - Práticas Conhecidas de Gestão Estratégica de Custos

\begin{tabular}{lcc}
\hline \multicolumn{1}{c}{ Práticas } & N & \% \\
\hline Custeio da Cadeia e Valor & 13 & 44,8 \\
Mensuração Integrada de Desempenho & 10 & 34,5 \\
Custo-Alvo (Target Cost) & 11 & 37,9 \\
Custeio do Ciclo de Vida & 9 & 31,0 \\
Monitoramento da Posição Competitiva & 4 & 13,8 \\
Gestão Baseada em Atividades (ABM) & 10 & 34,5 \\
Análise de Custo Kaizen & 8 & 27,6 \\
Precificação Estratégica & 7 & 24,1 \\
Análise de Custo dos Concorrentes & 8 & 27,6 \\
Custo Total de Uso e Propriedade (TCO) & 3 & 10,3 \\
Outras Práticas & 5 & 17,2 \\
Total de Participantes & $\mathbf{2 9}$ & $\mathbf{1 0 0 , 0}$ \\
\hline
\end{tabular}

A respeito das práticas de GEC declaradas como conhecidas, há consistência com o encontrado em outras pesquisas, tais como a de Cinquini e Tenucci (2006). No geral, há ainda espaço para melhor posicionamento quanto ao domínio das práticas pesquisadas. Esse resultado é consistente com o obtido por Quesado e Rodrigues (2007), os quais também detectaram baixo conhecimento sobre elas por profissionais portugueses.

\subsection{Principais Habilidades Pessoais}

Os dados da Tabela 2 destacam as habilidades pessoais que os respondentes julgam mais importantes. 
Um perfil de contadores de custos: Estudo com profissionais de empresas do polo industrial de

São Leopoldo, RS

Marco Antonio Souza, Tania Vanessa Sibirino Gomes

Tabela 2 - Habilidades Pessoais mais Importantes

\begin{tabular}{lcc}
\hline \multicolumn{1}{c}{ Habilidades } & N & $\mathbf{\%}$ \\
\hline Lideraça & 9 & 31,0 \\
Iniciativa & 17 & 58,6 \\
Flexibilidade para Mudanças & 7 & 24,1 \\
Facilidade de Relacionamento Interpessoal & 13 & 44,8 \\
Inovador & 1 & 3,4 \\
Domínio de Idiomas Estrangeiros & 2 & 6,9 \\
Transquilidade (Trabalho sob Pressão) & 16 & 55,2 \\
Capacidade de Dizer Não a Atos e Fatos que & & \\
$\quad$ Incorram em Riscos Fiscais e Societários & 11 & 37,9 \\
Poder de Persuasão e Convencimento & 11 & 37,9 \\
Total de Participantes & $\mathbf{2 9}$ & $\mathbf{1 0 0 , 0}$ \\
\hline
\end{tabular}

Há destaque para atuação sob pressão (55\%). Com menor indicação tem-se a facilidade de relacionamento interpessoal. Outras habilidades reconhecidas como importantes pela literatura são pouco referenciadas pelos respondentes: inovação (3\%), idioma estrangeiro (7\%) e flexibilidade para mudanças (27\%).

Entre outros, chama atenção que a capacidade de recusar a adoção de procedimentos que conduzam a riscos fiscais e societários compareça com apenas $38 \%$. Algumas dessas habilidades têm sido tratadas em outros estudos. A esse respeito, Perez Júnior, Oliveira e Costa (2010, p. 290) enfatizam que "[...] iniciativa, criatividade e capacidade empreendedora serão características que distinguirão os profissionais de sucesso [...]".

\subsection{Percepção dos Profissionais a Respeito da Contabilidade de Custos}

Apresenta-se a seguir percepção dos respondentes a respeito de alguns conceitos de custos e sobre o perfil do contador de custos quanto a algumas habilidades. Esta parte da pesquisa está direcionada a verificar a intensidade da concordância dos respondentes em relação a aspectos que caracterizam o perfil do contador de custos na atualidade. 
Um perfil de contadores de custos: Estudo com profissionais de empresas do polo industrial de

São Leopoldo, RS

Marco Antonio Souza, Tania Vanessa Sibirino Gomes

Para melhor entendimento dos resultados apresentados na Tabela 3, observase que quanto mais próximo o Ranking Médio (RM) for de cinco, maior é o grau de concordância dos respondentes às afirmativas.

Tabela 3 - Percepções a Respeito da Contabilidade de Custos

\begin{tabular}{|c|c|c|c|c|c|c|c|}
\hline Percepções & 1 & 2 & 3 & 4 & 5 & Total & RM \\
\hline $\begin{array}{l}\text { A finalidade da contabilidade de custos é a mensuração dos } \\
\text { estoques e do resultado econômico da empresa }\end{array}$ & - & 3 & 1 & 21 & 4 & 29 & 3,90 \\
\hline A contabilidade de custos consiste em informações relevant & & & & & & & \\
\hline para decisões gerenciais de curto e longo prazo & - & - & - & 21 & 8 & 29 & 4,28 \\
\hline $\mathrm{Na}$ atualidade o contador precisa desenvolver habilidades & & & & & & & \\
\hline pessoais e de gestão além das técnicas contábeis & - & - & - & 9 & 20 & 29 & 4,69 \\
\hline $\begin{array}{l}\text { Para a contabilidade de custos cumprir suas finalidades é } \\
\text { necessária a utilização de mais de um método de custeio }\end{array}$ & - & 4 & 6 & 14 & 5 & 29 & 3,69 \\
\hline Pelos conhecimentos acumulados sente-se apto a participar & & & & & & & \\
\hline GEC da empresa & 1 & 1 & 1 & 17 & 9 & 29 & 4,10 \\
\hline $\begin{array}{l}\text { O curso de graduação deu adequada base conceitual e prátic } \\
\text { para exercer atividades relacionadas a custos }\end{array}$ & 3 & 7 & 5 & 14 & - & 29 & 3,03 \\
\hline
\end{tabular}

Dos profissionais contábeis, $72 \%$ (RM de 3,9) concordam com a afirmativa de que a Contabilidade de Custos tem por finalidade mensurar os estoques e a avaliação do resultado econômico (DRE). Sobre a maior abrangência da contabilidade de custos no fornecimento de informações de curto e longo prazo, atividade típica da contabilidade gerencial, o grau de concordância entre os profissionais eleva-se para 4,28 , corroborando o entendimento dos profissionais a respeito da contabilidade de custos como importante ferramenta de gestão. O menor RM na primeira afirmativa pode indicar que os respondentes entenderam haver outras funções da contabilidade de custos além das assinaladas.

A terceira afirmativa trata de medir a percepção dos profissionais da contabilidade de custos a respeito do desenvolvimento também de suas habilidades pessoais e de gestão. $\mathrm{O}$ RM de 4,69 sinaliza uma forte concordância quanto à necessidade de incorporação dessas outras habilidades além do domínio das técnicas contábeis de custos. 
Um perfil de contadores de custos: Estudo com profissionais de empresas do polo industrial de

São Leopoldo, RS

Marco Antonio Souza, Tania Vanessa Sibirino Gomes

Com menor intensidade tem-se a concordância de se utilizar mais de um método de custeio, com RM situado em 3,69. Dado o reconhecimento de que os métodos de custeio têm características próprias e são mais aplicáveis a determinadas necessidades informacionais, considera-se baixo esse nível de concordância. Isso pode sinalizar que em boa parte dos casos as informações da área de custos são formatadas sob um único conceito, o por absorção, com maior foco fiscal. A literatura aborda as possíveis desvantagens desse tipo de procedimento.

A habilidade e preparo dos respondentes em participar da GEC da empresa revelou-se com patamar elevado, um RM de 4,1. Observa-se, portanto, que $90 \%$ dos participantes sentem-se aptos a participar das GEC, da organização. Esse resultado revela certa inconsistência em relação aos dados da Tabela 1, cujos resultados sinalizam um conhecimento apenas médio de algumas e muito baixo em outras práticas pesquisadas.

Por fim, cabe destacar a baixa concordância (mais próxima à neutralidade do RM 3) a respeito das contribuições do curso de graduação para a compreensão dos fundamentos de custos. Isso parece ratificar o entendimento de que o conhecimento principal adveio da atividade prática desenvolvida pelos participantes. Observa-se, entre as questões iniciais da pesquisa (seção 4.2), que 75\% dos respondentes começaram a atuar na área antes ou durante o curso de graduação. Assim, na ótica dos respondentes, parece que a influência da atividade prática na formação deles foi mais incisiva do que o curso regular de graduação.

\subsection{Análise Global dos Resultados}

Os resultados apresentados contribuem para delinear o perfil do contador de custos que atuam em indústrias de São Leopoldo. Pode-se dizer que eles possuem um satisfatório nível de formação acadêmica. Quanto a isso, há que se atentar para a recomendação de Franco (1999) quanto a necessidade de manter ênfase na educação continuada. Dado que o mercado tem exigido adequado nível de especialização, esta busca precisa ser melhorada. Evidencia-se que $70 \%$ dos profissionais possuem mais de 
Um perfil de contadores de custos: Estudo com profissionais de empresas do polo industrial de

São Leopoldo, RS

Marco Antonio Souza, Tania Vanessa Sibirino Gomes

seis anos de experiência na função, o que é algo positivo visto a estabilidade na função. Outra evidência obtida é que todos os profissionais estão em nível intermediário na hierarquia da organização, mas pode-se destacar a participação deles na gestão organizacional (72\% indicaram participação).

A respeito das habilidades técnicas os resultados sinalizam que parcela significativa dos participantes (38\%) está habituada a utilizar o método de absorção para fins gerenciais, o que deve ser revisto dado às críticas feitas a este método para tais finalidades. Talvez haja necessidade de maior iniciativa e inovação dos respondentes (habilidades pessoais) em utilizar outras abordagens de custeio, mais apropriadas para a geração do tipo de informação demandada. Das principais práticas de GEC conhecidas, sobre as quais a literatura da atualidade dá grande destaque, os resultados evidenciam que os profissionais que participaram do estudo ainda carecem de ampliar o conhecimento e adoção das novas práticas de gestão de custos relacionadas à formação do plano estratégico das empresas (Tabela 1). Isso fica caracterizado, mesmo com a percepção deles apresentada na Tabela 3.

Quanto às habilidades pessoais, os resultados sinalizam que a iniciativa é considerada a habilidade de maior importância entre os respondentes. Tais resultados corroboram o entendimento dado por Fleury e Fleury (2001), para os quais as competências vão além da esfera profissional e abarcam outras competências do indivíduo, dentre as quais a iniciativa. De fato, no geral há reconhecimento dos respondentes (Tabela 3), quanto à necessidade de desenvolvimento de outras habilidades (pessoais e de gestão) além das práticas contábeis.

\section{CONCLUSÃO}

Por meio desse estudo buscou-se delinear o perfil do contador de custos atuante em indústrias da cidade de São Leopoldo/RS. Para tanto, foram analisados os 29 questionários respondidos por profissionais responsáveis pela contabilidade de custos 
Um perfil de contadores de custos: Estudo com profissionais de empresas do polo industrial de

São Leopoldo, RS

Marco Antonio Souza, Tania Vanessa Sibirino Gomes

nas referidas indústrias. Além disso, foram identificadas através da análise da literatura as principais habilidades que delineiam o perfil do contador de custos na atualidade.

$\mathrm{Na}$ análise dos resultados e da literatura destacou-se o nível satisfatório de formação acadêmica dos respondentes, sendo que a metade deles possui ou está cursando graduação em Ciências Contábeis. Outro achado importante é que 30\% dos profissionais possuem uma pós-graduação (especialização), MBA, ou mestrado. Também, notou-se que a vivência prática é fonte fundamental para o aprendizado profissional, sendo citada por $93 \%$ dos profissionais, e que $38 \%$ dos respondentes têm mais de 15 anos de atividade, o que consolida a experiência prática na função.

Constatou-se, também, que a competência profissional dos respondentes não está ligada somente a conhecimentos teóricos e empíricos, mas diretamente ligada à prática profissional, o que corrobora a literatura apresentada. Que há participação dos respondentes no processo decisório e na formação da estratégia organizacional. Esse dado é significante, situado em $72 \%$ dos participantes.

Das habilidades pessoais mais valorizadas pelos respondentes destacam-se a iniciativa e o relacionamento interpessoal. Os resultados obtidos estão em concordância com a literatura. De outra parte, conforme Cardoso (2006), as competências requeridas aos contadores de custos pelas organizações é algo dinâmico e sofre influência de mudanças ambientais. Isso significa que as habilidades pessoais devem ser revisadas e avaliadas continuamente, acompanhando as necessidades das organizações e demandas de um mercado de concorrência acirrada.

Cabe destacar, no perfil dos contadores de custos das indústrias de São Leopoldo/RS que participaram da amostra, o nível de formação e tempo de experiência profissional. Outro achado que merece estudo mais detalhado refere-se ao ensino da graduação. De acordo com os respondentes, essa formação não foi suficiente para uma boa formação conceitual e prática.

Apesar do entendimento de que o objetivo geral e os objetivos específicos propostos foram atingidos, o desenvolvimento do estudo sinaliza a necessidade de mais pesquisas sobre essa temática relacionada com a identificação do perfil dos 
Um perfil de contadores de custos: Estudo com profissionais de empresas do polo industrial de

São Leopoldo, RS

Marco Antonio Souza, Tania Vanessa Sibirino Gomes

profissionais que atuam na área de custos. Uma das principais indicações é a realização de pesquisa mais abrangente, com envolvendo diferentes segmentos de negócio, inclusive da área de serviços. Acredita-se que estudos com esse foco contribuem para superar as principais limitações apresentadas nesse estudo.

Quando possível foram feitas análises comparativas com outros estudos nacionais. Há que se destacar, entretanto, a necessidade de análises comparativas dos resultados nacionais com aqueles apresentados por pesquisas internacionais da mesma natureza. De fato, dada a dinâmica globalizada dos negócios, há que se investigar um perfil que possivelmente atenda as exigências ditadas pela gestão global e não com foco apenas nas demandas locais.

\section{REFERÊNCIAS}

AMERICAN INSTITUTE OF CERTIFIED PUBLIC ACCOUNTANTS - AICPA. (2011). Results of CPA horizons 2025: core competencies. Disponível em: <http://www.aicpa.org/ research/cpahorizons2025/topfives/corecompetencies/pages/corecompetencies.aspx>. Acesso em: 17/out/2011.

BALLESTERO, Maria E. A. (2001). Administração da qualidade e produtividade. São Paulo: Atlas.

BANCO NACIONAL DE DESENVOLVIMENTO ECONÔMICO E SOCIAL - BNDES. (2010). Carta Circular no 10/2010: normas relativas ao porte das beneficiárias.

CALLADO, Aldo Leonardo Cunha; MIRANDA, Luiz Carlos; CALLADO, Antonio Andre Cunha. (2003). O perfil do gestor de custos: um estudo do setor de confecções de João Pessoa. Contabilidade Vista \& Revista, v. 14, n. 3, p. 9-25, dez.

CARDOSO, Ricardo Lopes. (2006). Competência do contador: um estudo empírico. (Tese de Doutorado). Programa de Pós-Graduação em Ciências Contábeis, Universidade de São Paulo. São Paulo, FEA/USP.

CARDOSO, Jorge Luiz; SOUZA, Marcos Antonio; ALMEIDA, Lauro Brito. (2006). Perfil do contador na atualidade: um estudo exploratório. BASE, v. 3, n. 3, p. 275-284, set./dez.

CARVALHO, Sérgio Ribeiro. (2009). O contador líder: como o profissional deve trilhar os novos caminhos da contabilidade. São Paulo: IOB. 
Um perfil de contadores de custos: Estudo com profissionais de empresas do polo industrial de

São Leopoldo, RS

Marco Antonio Souza, Tania Vanessa Sibirino Gomes

CINQUINI, L. TENUCCI, A. (2011). Strategic management accounting: exploring distinctive features and links with strategy. Disponível em: http://mpra.ub.uni.muenchen.de/212/. Acesso em: 20/out.

COSENZA, P. C. (2001). Perspectivas para a profissão contábil num mundo globalizado: um estudo a partir da experiência brasileira. Revista do CFC, ano XXX, n. 130, p. 42-63.

DURAND, Thomas. (1998). Forms of incompetence. In: Proceedings Fourth International Conference on Competence-Based Management. Oslo: Norwegian School Management.

DUTRA, Joel Souza. (2007). Competências: conceitos e instrumentos para a gestão de pessoas na empresa moderna. São Paulo: Atlas.

FLEURY, Afonso C. C.; FLEURY, Maria T. L. (2001). Estratégias empresariais e formação de competências: um quebra-cabeça caleidoscópico da indústria brasileira. (2 ed.). São Paulo: Atlas.

FRANCO, Hilário. (1999). Contabilidade na era da globalização. São Paulo: Atlas.

FRIEDRICH, João; ALMEIDA, Cláudia Carrano. (2011). A gestão ambiental sob a ótica contábil. In: CONVENÇÃO DE CONTABILIDADE DO RIO GRANDE DO SUL, 9. 2003. Anais... Gramado, CRC-RS. Disponível em: <http://www.ccontabeis.com.br/conv/t23.pdf>. Acesso: 10/out.

GIL, Antonio Carlos. (2010). Como elaborar projetos de pesquisa. (5 ed.). São Paulo: Atlas.

HANSEN, Don R.; MOWEN, Maryanne M. (2001). Gestão de custos. São Paulo: Pioneira.

IUDÍCIBUS, Sérgio de; MARTINS Eliseu; CARVALHO Nelson L. (2005). Contabilidade: aspectos relevantes da epopéia de sua evolução. Revista Contabilidade e Finanças, São Paulo, v.16, n. 38, maio/ago.

KAVCIC, Slavka; MIHELCIC, Eva. (2006). Accounting skills hotel enterprises need today. Tourism and hospitality management, v. 12, n. 1, p. 19-34.

LE BOTERF, Guy. (2003). Desenvolvendo a competência dos profissionais. Porto Alegre: Artmed. 
Um perfil de contadores de custos: Estudo com profissionais de empresas do polo industrial de

São Leopoldo, RS

Marco Antonio Souza, Tania Vanessa Sibirino Gomes

LEONE, G. S. G.; LEONE, R. J. G. (2010). Curso de contabilidade de custos. São Paulo: Atlas.

LOTHIAN, Niall. (1977). Managerial implications of current cost accounting. Management Decision, v. 15, n. 4, p. 357-366.

MARTINS, Eliseu. (2003). Contabilidade de custos. (9 ed.). São Paulo: Atlas.

MCGEE, James; PRUSAK, Laurence. (1994). Gerenciamento estratégico da informação: aumente a competitividade e a eficiência de sua empresa utilizando a informação como uma ferramenta estratégica. (10 ed.). Rio de Janeiro: Campus.

MOHAMED, Ehab K.A.; LASHINE, Sherif F. (2003). Accounting knowledge and skills and challenges of a global business environmental. Managerial Finance, v. 29, n. 7, p. 3-16.

PEREZ JÚNIOR, José Hernandez; OLIVEIRA, Luís Martins; COSTA, Rogério Guedes. (2010). Gestão estratégica de custos. (6 ed.). São Paulo: Atlas.

PIRES, Barbosa Charline. (2008). A formação e a demanda do mercado de trabalho do contador na região metropolitana de Porto Alegre - RS. (Dissertação de Mestrado). Programa de Pós-Graduação em Ciências Contábeis, Universidade do Vale do Rio dos Sinos. São Leopoldo.

PORTER, Michael E. (1998). Estratégia competitiva. (16 ed.). Rio de Janeiro: Campus.

PREFEITURA MUNICIPAL DE SÃO LEOPOLDO. (2011). Departamento de Desenvolvimento Empresarial. Texto postado no hiperlink Secretarias: Desenvolvimento. Disponível

em:<https://www.saoleopoldo.rs.gov.br/home/show_page.asp?id_CONTEUDO=1294\&codID CAT $=1 \&$ id_SERVICO $=\& I D \_L I N K \_P A I=24 \&$ categoria $=<b>$ Secretarias $</ b>$ Acesso: em: 30/jul.

QUESADO, Patrícia R.; RODRIGUES, Lucia L. (2007). A gestão estratégica de custos em grandes empresas portuguesas. Revista Ibero Americana de Contabilidad de Gestión, v. 1, n. 10, p. 121-143.

RAUPP, Fabiano M.; AMBONI, Nérico; CUNHA, Daniela R.; DUARTE, Juliana F.; AGOSTINETO, Raquel C. (2009). O ensino da contabilidade de custos nos cursos de graduação em administração do Estado de Santa Catarina. ABCustos, v. 4, n. 2, p. 6179, maio/ago. 
Um perfil de contadores de custos: Estudo com profissionais de empresas do polo industrial de

São Leopoldo, RS

Marco Antonio Souza, Tania Vanessa Sibirino Gomes

ROESCH, Sylvia M. A. (2010). Projetos de estágio e de pesquisa em administração. 3. Ed. São Paulo: Atlas.

ROSA, Morgana L. (2008). Características e tendências para o perfil profissional do contador. Trabalho de Conclusão de Curso. Universidade FEEVALE. Novo Hamburgo.

SHANK, J. K.; GOVINDARAJAN, V. (1997). A revolução dos custos. (2. ed.). Rio de Janeiro: Campus.

SILVA, Flávia F.; MIRANDA, Luiz C. (2002). O perfil do profissional de custos na indústria de transformação do estado de Pernambuco. In: CONGRESSO BRASILEIRO DE CUSTOS, 9. Anais... ABC, São Paulo, 2002 - CD-ROM.

SIMMONDS, Kenneth. (1981). Strategic management accounting. Management Accounting, v. 59, n. 4, p. 26-29, april.

SINDICATO DOS CONTABILISTAS DO ESTADO DE SÃO PAULO - SINDCONTSP. (2005). Fatos contemporâneos redesenham o perfil do contabilista. 2005. Disponível em: www.sindcontsp.org.br/rpc\%20487.doc. Acesso em: 30/out/2011.

VERGARA, Sylvia H. C. (2000). Projetos e relatórios de pesquisa em administração. São Paulo: Atlas.

WILMSHURST, T. D.; FROST, G. R. (2001). The role of accounting and the accountant in the environmental management system. Business Strategy and the Environment, $\mathrm{v}$. 10 , n. 3, p. 135-147.

XAVIER, Ricardo de Almeida Prado. (2006). Sua carreira: planejamento e gestão como desenvolver melhor seus talentos e competências. São Paulo: Pearson.

ZARIFIAN, Philippe. (2001). Objetivo competência: por uma nova lógica. São Paulo: Atlas.

Data de Submissão: 24/02/2012

Data de Aceite: 12/05/2014 